\title{
Mechanical properties of coated superelastic archwires in conventional and self-ligating orthodontic brackets
}

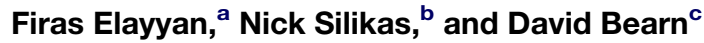 \\ Ramallah, Palestine, and Manchester and Dundee, United Kingdom
}

\begin{abstract}
Introduction: Coated archwires have been introduced to improve esthetics during orthodontic treatment. Our aim was to investigate the mechanical properties of coated superelastic archwires compared with conventional superelastic archwires with conventional and self-ligating brackets. Methods: Four types of orthodontic archwires were investigated, 2 superelastic nickel-titanium and 2 coated Ultraesthetic archwires in 0.016-in and $0.018 \times 0.025$-in dimensions (all from G\&H Wire, Greenwood, Ind). To achieve the same nominal size, the coated archwire is constructed from a smaller archwire that, when coated, reaches the nominal dimensions stated for the archwire. Conventional edgewise Orthos and Damon 2 self-ligating brackets (both from Ormco, Orange, Calif) were used with each wire. All specimens were tested in a universal testing machine in a 3-point bending test at a speed of $1 \mathrm{~mm}$ per minute and deflected for $2 \mathrm{~mm}$. Loading and unloading forces were recorded and load-deflection curves plotted. Results: Coated superelastic wires produced statistically significantly lower forces in loading and unloading when compared with the superelastic nickel-titanium wires at most archwire deflections $(P<0.01)$. For nickel-titanium wires, loading values ranged from 189 to $1202 \mathrm{~g}$, whereas the respective values for coated wires were 124 to $772 \mathrm{~g}$. For all wires, an increase in size resulted in an increase in force. Interactions between wire type (coated or uncoated) and bracket type were observed. Conclusions: Ultraesthetic coated archwires produced lower force values in loading and unloading compared with uncoated wires of same nominal size. The Damon 2 self-ligating bracket system produced lower force values in loading and unloading. The lowest forces were generated by the combination of Ultraesthetic coated archwires and Damon 2 self-ligating brackets. (Am J Orthod Dentofacial Orthop 2010;137:213-7)
\end{abstract}

$\mathbf{T}$ he demand for esthetic orthodontic appliances is increasing, and development of materials with acceptable esthetics for patients and adequate clinical performance for clinicians is needed. Esthetics of orthodontic appliances have improved significantly with the use of the latest esthetic transparent brackets made of ceramics or composites. ${ }^{1}$ There are 2 forms of esthetic orthodontic archwires: fiber-reinforced composite $^{2,3}$ and coated metal. Fiber-reinforced wires are still experimental and not available commercially, but they look promising for the future of esthetic archwires. ${ }^{4,5}$

\footnotetext{
${ }^{\text {a }}$ Private practice, Ramallah, Palestine.

becturer, dental biomaterials science, School of Dentistry, University of Manchester, Manchester, United Kingdom.

${ }^{\mathrm{c}}$ Professor, orthodontics, Dental School, University of Dundee, Dundee, United Kingdom.

The authors report no commercial, proprietary, or financial interest in the products or companies described in this article.

Reprint requests to: David Bearn, Dental School, University of Dundee, Park Place, Dundee, DD1 4HN, United Kingdom; e-mail, d.bearn@dundee.ac.uk. Submitted, November 2007; revised and accepted, January 2008. $0889-5406 / \$ 36.00$

Copyright $(2010$ by the American Association of Orthodontists. doi:10.1016/j.ajodo.2008.01.026
}

Coated metallic archwires are currently the only esthetic orthodontic archwires available for clinical use. Materials used in coating are plastic resin materials such as synthetic fluorine-containing resin or epoxy resin composed mainly of polytetrafluoroethylyene to simulate tooth color. ${ }^{6}$ The epoxy coating is manufactured with a depository process that plates the base wire with an epoxy resin of approximately 0.002 in thick. Thus, a strong adhesion is achieved between the epoxy coating and the wire. ${ }^{7}$

When the frictional behavior of plastic-coated archwires was compared with noncoated reference wires by the same manufacturer, plastic coating was found to have a significant effect in decreasing friction. In contrast, Proffit ${ }^{8}$ described this coat as "undurable." Kusy $^{2}$ found that, when coated, the colored wires are routinely damaged from forces of mastication and activity of the enzymes in the oral cavity within 3 weeks of their use in vivo. ${ }^{2,5}$ Other authors also encountered difficulties with these coated archwires, claiming that the color tends to change with time and the coating splits during usage in the mouth, exposing the underlying metal. ${ }^{4,9}$ However, despite these problems with the durability of the coating, these wires continue to be 


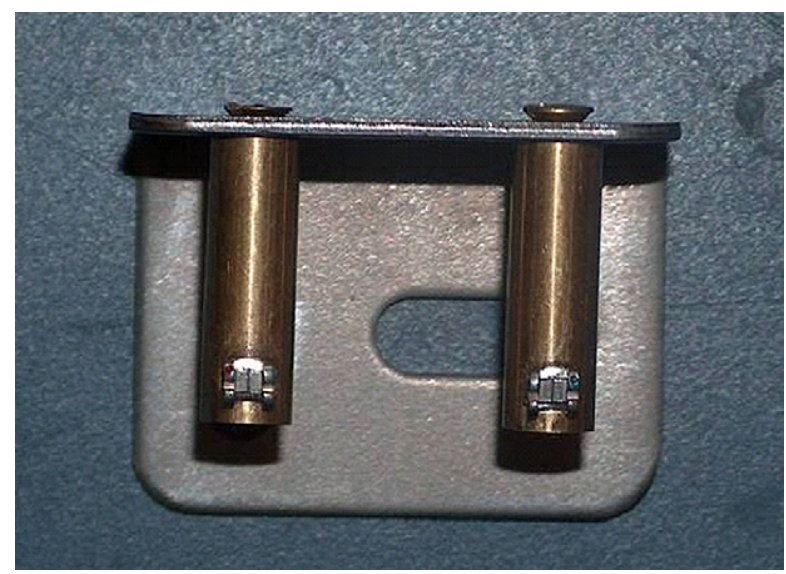

Fig 1. Testing jig showing conventional twin brackets bonded to the arms of the jig.

marketed and used in clinical practices, even though no studies have examined their mechanical properties.

The test used to measure the stiffness of orthodontic archwires is the 3-point bending test. It assesses loaddeflection properties; this is considered the most important parameter in determining the biologic nature of tooth movement. ${ }^{10,11}$ The advantages of this test are its close simulation to clinical application, its ability to differentiate wires with superelastic properties, and the high degree of reproducibility. ${ }^{12}$ Nikolai and Chung $^{13}$ reported that, with large deflections, the wire could buckle, with a decrease in unloading force. It is unclear whether this mimics the clinical situation, but it highlights the need for caution when relating mechanical property data to a clinical scenario.

The aim of this study was to investigate the mechanical properties of coated esthetic superelastic archwires in a 3-point bending test compared with conventional superelastic archwires with conventional and self-ligating brackets.

The null hypotheses were (1) there is no difference in load-deflection properties between coated and uncoated superelastic wires of the same size; and (2) there is no difference in load-deflection properties of archwires between conventional and self-ligating brackets.

\section{MATERIAL AND METHODS}

Four types of orthodontic archwires were investigated: superelastic nickel-titanium (NiTi) and coated Ultraesthetic archwires with sizes of 0.016 in and $0.018 \times 0.025$ in. All wires were manufactured by G\&H Wire (Greenwood, Ind). According to the manufacturer, Ultraesthetic wires are superelastic NiTi wires coated with an epoxy layer of .002 in thick. A special jig
(Fig 1) with 2 parallel brass rods, $5 \mathrm{~mm}$ in diameter, was designed and constructed. Two stainless steel Orthos edgewise central-incisor brackets (Ormco, Orange, Calif) with a slot size of $0.022 \times 0.028$ in were bonded onto the top of these rods with an interbracket distance of $14 \mathrm{~mm}$, equivalent to the distance between the central incisor and canine bracket. The jig was fixed to the base of the universal testing machine (Zwick/Roell Z020, Zwick GmbH, Ulm, Germany). The wire specimen was attached to the brackets with elastomeric ligatures. Two self-ligating Damon 2 brackets (Ormco) were bonded at the same interbracket distance. The force was applied by using a third brass rod attached to the moving part of the testing machine heading vertically toward the middle of the interbracket distance at a crosshead speed of $1 \mathrm{~mm}$ per minute. The middle portion of the wire was deflected $2 \mathrm{~mm}$ and then unloaded at the same speed. The loading and unloading forces were registered by the load cell, and the results were analyzed with testXpert software (Zwick GmbH).

Sample size calculations for detecting $10 \%$ differences in these values suggested testing 10 archwires in each group. Two-way analysis of variance (ANOVA) was used to identify main effects (differences between bracket types and between wire types), and the effects of the interactions between different wire types and bracket types. All statistical tests were undertaken at the $P<0.05$ level of significance.

\section{RESULTS}

For the archwire sizes and types, means forces for 0.016-in superelastic NiTi and Ultraesthetic coated wires with conventional and self-ligating orthodontic brackets are shown in Table I, and the load-deflection curves are given in Figure 2. Force increased as deflection increased. Coated wires resulted in lower forces, ranging from 18 to $192 \mathrm{~g}$ for the 0.5- and 2-mm deflections, respectively. NiTi wires ranged from 29 to $252 \mathrm{~g}$ for the 0.5 - and 2-mm deflections, respectively.

The results for the $0.018 \times 0.025$-in wires are shown in Table II and Figure 3. Greater changes were observed for these wires. Forces in the coated wires ranged from 60 to $772 \mathrm{~g}$ for the 0.5 - and 2-mm deflections, respectively; forces for the NiTi were 99 to $1202 \mathrm{~g}$.

For the archwire and bracket combinations, the results of the 2-way ANOVA are shown in Table III for the 0.016 -in and $0.018 \times 0.025$-in archwires at each deflection. For the 0.016 -in wire at the 0.5 -mm deflection, there was no significant effect of wire or bracket type. For the 0.016-in wires, wire type had a significant effect $(P<0.01)$ at all other deflections, with lower forces for coated NiTi wires. Bracket type was a significant effect 
Table I. Loading and unloading mean forces (standard deviations in parentheses) for the 0.016-in archwires

\begin{tabular}{|c|c|c|c|c|c|c|c|c|}
\hline \multirow[b]{2}{*}{ Wire } & \multicolumn{2}{|c|}{$\begin{array}{l}\text { Loading force } \\
\text { (g) at 2-mm deflection }\end{array}$} & \multicolumn{2}{|c|}{$\begin{array}{l}\text { Unloading force } \\
\text { (g) at 1.5-mm deflection }\end{array}$} & \multicolumn{2}{|c|}{$\begin{array}{l}\text { Unloading force } \\
\text { (g) at 1-mm deflection }\end{array}$} & \multicolumn{2}{|c|}{$\begin{array}{l}\text { Unloading force } \\
\text { (g) at 0.5-mm deflection }\end{array}$} \\
\hline & Ligature & Self-ligation & Ligature & Self-ligation & Ligature & Self-ligation & Ligature & Self-ligation \\
\hline $\mathrm{NiTi}$ & $252(17)$ & 189 (13) & $80(14)$ & 89.7 (13) & $48(11)$ & $56(13)$ & $29(14)$ & $30(12)$ \\
\hline Coated NiTi & $192(20)$ & 124 (12) & $59(12)$ & $60(13)$ & $46(9)$ & $36(8)$ & $29(10)$ & $18(6)$ \\
\hline
\end{tabular}

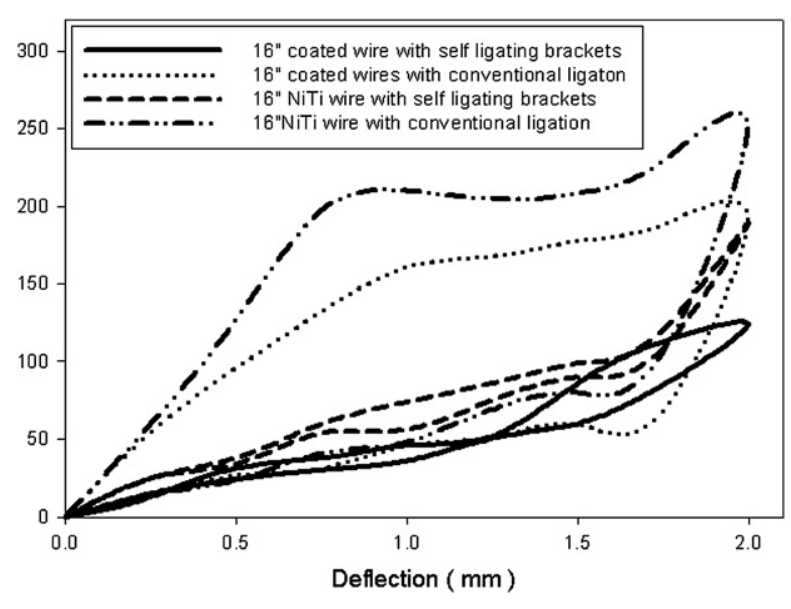

Fig 2. Loading and unloading force (g) and deflection $(\mathrm{mm})$ curves for 0.016-in archwires.

at the 2-mm loading deflection only with lower forces for self-ligating brackets. The direction of the differences showed lower forces in the coated and selfligation combination, and higher unloading forces in the uncoated and self-ligation combination. For the $0.018 \times 0.025$-in wire, there were significant effects of wire and bracket type at all deflections, with coated NiTi wires producing lower forces, and self-ligation producing lower forces.

\section{DISCUSSION}

The 3-point bending tests produced load-deflection diagrams consisting of an upper loading curve and a lower unloading curve. The vertical difference between them is the combined effect of hysteresis in the material and the effects of friction between archwire and bracket. The loading curve represents the force needed to engage the wire in the bracket, whereas the unloading curve represents the forces delivered to teeth during the levelling and aligning stage of treatment. ${ }^{14}$

For the 0.016-in archwires, the coated archwires produced a lower force in both loading and unloading than did the uncoated wires $(P<0.01$ at $1.0-$ and $1.5-\mathrm{mm}$ unloading and $2.0-\mathrm{mm}$ loading deflection). This is almost certainly because coated wires contain a smaller diameter $\mathrm{NiTi}$ archwire inside to compensate for the thickness of the coating layer. ${ }^{15,16}$ However, many orthodontists are likely to use the nominal wire size as their guide in certain clinical situations. These results highlight the importance of considering larger nominal diameter wires than would normally be selected when using coated archwires.

The $0.018 \times 0.025$-in coated wires also showed lower loading and unloading forces compared with the uncoated wires, again most likely because of the decrease in the size of the active NiTi wires in them. This was a significant effect at all deflections.

With the 0.016-in archwires, the type of bracket was a significant effect at the 2 -mm loading. With the $0.018 \times 0.025$-in archwires, the type of bracket was a significant effect at all deflections, with lower loading and unloading forces in the self-ligating brackets.

This effect might be because of greater frictional forces in the conventional bracket system and greater damage to the surface of the coated wires in these brackets that further increases the friction. Friction between wire, bracket, and ligature is important in determining the amount of force delivered by the wire, and, as the deflection increases, so the angle of emergence of the wire from the bracket becomes more acute. This produces greater frictional resistance and is likely to lead to more damage to the coating. During the loading phase, this friction increases the measured force, but, in the unloading phase, friction decreases the force produced by the wires. ${ }^{14}$ Self-ligating bracket systems have been shown to decrease the amount of friction compared with elastomeric ligatures, and this would be expected to translate to decreased loading forces and increased unloading forces. ${ }^{17}$ Our results, however, showed decreases in both loading and unloading forces with the Damon 2 brackets, suggesting that another factor is involved. This might be the effect of ligation method on interbracket span, which influences the length of wire being deflected and thus the force generated. In this study, the brackets were placed at the same interbracket distance to simulate the clinical situation. When a ligature is placed around the conventional bracket, the bracket width is effectively increased, and the interbracket span is reduced. Conversely, the 
Table II. Loading and unloading mean forced (standard deviations in parentheses) for the $0.018 \times 0.025$-in archwires

\begin{tabular}{|c|c|c|c|c|c|c|c|c|}
\hline \multirow[b]{2}{*}{ Wire } & \multicolumn{2}{|c|}{$\begin{array}{l}\text { Loading force } \\
\text { (g) at 2-mm deflection }\end{array}$} & \multicolumn{2}{|c|}{$\begin{array}{l}\text { Unloading force } \\
\text { (g) at 1.5-mm deflection }\end{array}$} & \multicolumn{2}{|c|}{$\begin{array}{l}\text { Unloading force } \\
\text { (g) at 1-mm deflection }\end{array}$} & \multicolumn{2}{|c|}{$\begin{array}{l}\text { Unloading force } \\
\text { (g) at 0.5-mm deflection }\end{array}$} \\
\hline & Ligature & Self-ligation & Ligature & Self-ligation & Ligature & Self-ligation & Ligature & Self- ligation \\
\hline NiTi & $1202(33)$ & 979 (33) & $524(24)$ & $411(44)$ & $295(26)$ & $228(33)$ & $121(16)$ & $99(35)$ \\
\hline Coated NiTi & 772 (44) & $672(40)$ & $342(24)$ & $260(15)$ & $216(18)$ & $132(25)$ & 147 (32) & $60(14)$ \\
\hline
\end{tabular}

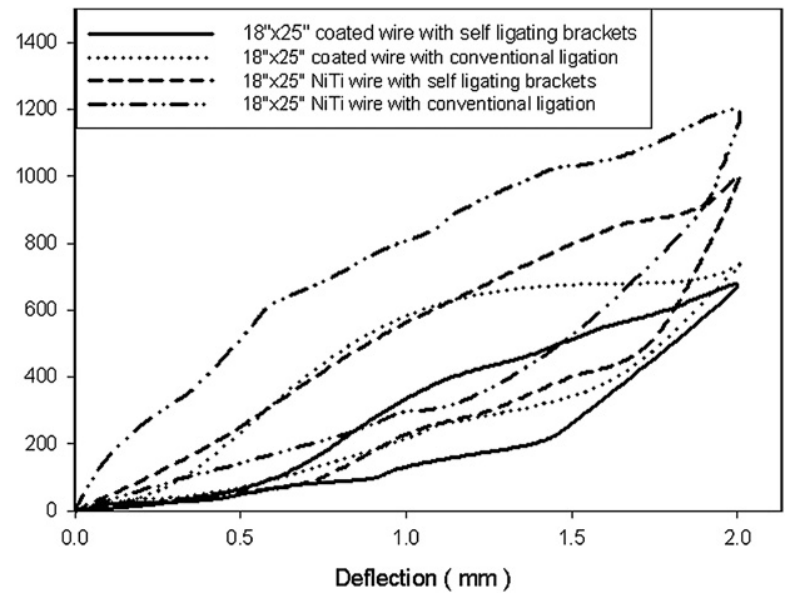

Fig 3. Loading and unloading force (g) and deflection $(\mathrm{mm})$ curves for $0.018 \times 0.025$-in archwires.

mechanism in the Damon 2 bracket produces an area of ligation that is narrower than the bracket itself, thus increasing the interbracket span. In changing the interbracket span, the emergence angle and the potential for damage to the surface of the wire are also changed. It can be seen, therefore, that a complex interaction occurs during loading and unloading, both in vitro and in vivo, and the combination of effects produced by the Damon 2 bracket result in lower forces in both loading and unloading.

This study highlights differences between types of archwires and brackets. We concluded that the combination of Damon 2 self-ligating brackets and Ultraesthetic coated wires delivers the lowest forces in both loading and unloading, and the combination of uncoated NiTi wires and conventional ligation delivers the highest forces.

\section{CONCLUSIONS}

1. Ultraesthetic coated archwires produced lower loading and unloading forces than uncoated wires of the same nominal dimensions.

2. Damon 2 self-ligating brackets produced lower loading and unloading forces compared with Or-
Table III. Results of ANOVA for each wire dimension and deflection showing the statistical significance $(P$ value) of the main effects (wire type and bracket type) and the wire-bracket interactions

\begin{tabular}{llr}
\hline $\begin{array}{l}\text { Wire size } \\
\text { and deflection } \\
\text { combination }\end{array}$ & \multicolumn{1}{c}{ Effect } & P value \\
\hline .016 -in at $2 \mathrm{~mm}$ & Wire type & $<0.001$ \\
& Bracket type & $<0.001$ \\
& Wire*bracket interaction & 0.556 \\
.016 -in at $1.5 \mathrm{~mm}$ & Wire type & $<0.001$ \\
& Bracket type & 0.198 \\
& Wire*bracket interaction & 0.338 \\
.016 -in at $1 \mathrm{~mm}$ & Wire type & 0.002 \\
& Bracket type & 0.820 \\
& Wire*bracket interaction & 0.012 \\
.016 -in at $0.5 \mathrm{~mm}$ & Wire type & 0.081 \\
& Bracket type & 0.174 \\
& Wire*bracket interaction & 0.102 \\
$.018 \times .025$-in at $2 \mathrm{~mm}$ & Wire type & $<0.001$ \\
& Bracket type & $<0.001$ \\
& Wire*bracket interaction & $<0.001$ \\
$.018 \times .025$-in at $1.5 \mathrm{~mm}$ & Wire type & $<0.001$ \\
& Bracket type & $<0.001$ \\
& Wire*bracket interaction & 0.093 \\
$.018 \times .025$-in at $1 \mathrm{~mm}$ & Wire type & $<0.001$ \\
& Bracket type & $<0.001$ \\
& Wire*bracket interaction & 0.333 \\
$.018 \times .025$-in at $0.5 \mathrm{~mm}$ & Wire type & $<0.001$ \\
& Bracket type & $<0.001$ \\
& Wire*bracket interaction & 0.464 \\
\hline & &
\end{tabular}

thos conventionally ligated brackets with $0.018 \times$ 0.025 -in wire.

3. Damon 2 self-ligating brackets produced a lower force at the 2-mm loading deflection with 0.016in wire.

4. The combination of Damon 2 self-ligating brackets and Ultraesthetic coated wires delivered the lowest forces in both loading and unloading.

\section{REFERENCES}

1. Russell JS. Aesthetic orthodontic brackets. J Orthod 2005;32: 146-63.

2. Kusy RP. A review of contemporary archwires: their properties and characteristics. Angle Orthod 1997;67:197-207. 
3. Zufall SW, Kusy RP. Sliding mechanics of coated composite wires and the development of an engineering model for binding. Angle Orthod 2000;70:34-47.

4. Lim KF, Lew KK, Toh SL. Bending stiffness of two aesthetic orthodontic archwires: an in vitro comparative study. Clin Mater 1994;16:63-71.

5. Kusy RP. Orthodontic biomaterials: from the past to the present. Angle Orthod 2002;72:501-12.

6. Ramadan AA. Removing hepatitis $\mathrm{C}$ virus from polytetrafluoroethylene-coated orthodontic archwires and other dental instruments. East Mediterr Health J 2003;9:274-8.

7. Clocheret K, Willems G, Carels C, Celis JP. Dynamic frictional behaviour of orthodontic archwires and brackets. Eur J Orthod 2004;26:163-70.

8. Proffit W. Contemporary orthodontics. St Louis: Mosby; 2000.

9. Postlethwaite KM. Advances in fixed appliance design and use: 1. Brackets and archwires. Dent Update 1992;19:276-80.

10. Krishnan V, Kumar KJ. Weld characteristics of orthodontic archwire materials. Angle Orthod 2004;74:533-8.
11. Kapila S, Sachdeva R. Mechanical properties and clinical applications of orthodontic wires. Am J Orthod Dentofacial Orthop 1989; 96:100-9.

12. Wilkinson PD, Dysart PS, Hood JA, Herbison GP. Load-deflection characteristics of superelastic nickel-titanium orthodontic wires. Am J Orthod Dentofacial Orthop 2002;121:483-95.

13. Nikolai RJ, Chung AY. Controlled localized buckling responses of orthodontic arch wires. Am J Orthod Dentofacial Orthop 1999; 116:308-16

14. Segner D, Ibe D. Properties of superelastic wires and their relevance to orthodontic treatment. Eur J Orthod 1995;17:395-402.

15. Burstone CJ. Variable-modulus orthodontics. Am J Orthod 1981; 80:1-16.

16. Kusy RP. On the use of nomograms to determine the elastic property ratios of orthodontic arch wires. Am J Orthod 1983;83: 374-81.

17. Voudouris JC. Interactive edgewise mechanisms: form and function comparison with conventional edgewise brackets. Am J Orthod Dentofacial Orthop 1997;111:119-40. 